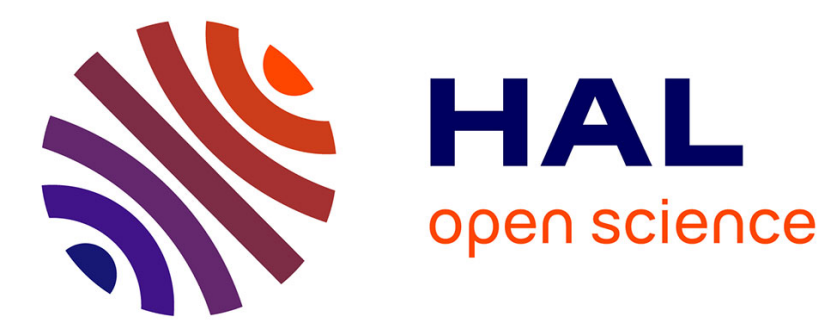

\title{
Linguistic negation and 2-tuple fuzzy linguistic representation model: a new proposal
}

Isis Truck, Nesrin Halouani, Souhail Jebali

\section{To cite this version:}

Isis Truck, Nesrin Halouani, Souhail Jebali. Linguistic negation and 2-tuple fuzzy linguistic representation model: a new proposal. Conference on Uncertainty Modelling in Knowledge Engineering and Decision Making (FLINS 2016), 2016, Roubaix, France. pp.81-86, 10.1142/9789813146976_0016 . hal-02877310

\section{HAL Id: hal-02877310 https://hal.science/hal-02877310}

Submitted on 22 Jun 2020

HAL is a multi-disciplinary open access archive for the deposit and dissemination of scientific research documents, whether they are published or not. The documents may come from teaching and research institutions in France or abroad, or from public or private research centers.
L'archive ouverte pluridisciplinaire HAL, est destinée au dépôt et à la diffusion de documents scientifiques de niveau recherche, publiés ou non, émanant des établissements d'enseignement et de recherche français ou étrangers, des laboratoires publics ou privés. 


\title{
Linguistic negation and 2-tuple fuzzy linguistic representation model: a new proposal
}

\author{
Isis TRUCK $^{1, *}$, Nesrin HALOUANI ${ }^{2, \dagger}$ and Souhail JEBALI ${ }^{1}$ \\ ${ }^{1}$ CHArt - EA4004, Paris 8 University, \\ Saint-Denis, F-93526, France \\ *E-mail: isis.truck@univ-paris8.fr \\ www.univ-paris8.fr \\ ${ }^{2}$ Unité de Logistique, Gestion Industrielle et Qualité (LOGIQ), \\ University of Sfax, Sfax, Tunisia \\ ${ }^{\dagger}$ E-mail: halouani.nesrin@gmail.com
}

\begin{abstract}
In this paper we focus on linguistic negation, i.e. the way to handle negative statements while making a decision. Indeed negation is an important issue in decision making, especially when data are provided by human beings where vagueness, ignorance and uncertainty are high. This article highlights the existing works about negation in semiotics and semantics. It is an attempt to give clues to model linguistic negation while building bridges between the 2-tuple fuzzy linguistic representation model and semantics.
\end{abstract}

Keywords: Linguistic negation and contradiction, vagueness, 2-tuple fuzzy linguistic representation model.

\section{Introduction}

Decision making is a widely known area for researchers since decades [1]. It deals with computing with words [2] as soon as decisions are made for human beings and/or come from linguistic data such as preferences, feelings, opinions, perceptions, etc., and errors may occur as a result due to ignorance, vagueness or uncertainty. In particular, linguistic data may represent judgements or comments such as those that can be found in narrative report cards for pupils, or opinions drawn up on patients by doctors in a hospital, etc.

Many models to deal with such data have been proposed, such as fuzzy sets [3], fuzzy linguistic 2-tuples [4,5] which exhibit linguistic terms expressed as a pair $\left(s_{i}, \alpha\right)$ where $s_{i}$ is a term and $\alpha$ a symbolic translation, proportional 2-tuples [6] or semantic 2-tuples [7]. However, the problem still 
offers a wide range of potential research subjects because words don't have "good mathematical properties" as numbers of course have. For example the issue of polarity (affirmative vs. negative terms) is not easy to tackle because linguistic negation is much more complicated than logical negation [8-10]. Negation, as a unique feature of human communication [11], has also been addressed from a linguistic, logical and psycholinguistic point of view [12-14]. From Aristotle's original square of opposition (where A and $\mathrm{E}$ are contraries, $\mathrm{I}$ and $\mathrm{O}$ are sub-contraries and $\mathrm{A}$ and $\mathrm{O}$ as well as $\mathrm{E}$ and I are contradictories, see Table 1) to Greimas' semiotic square [15], there still remains several ways to consider the linguistic negation.

Table 1. The Four Aristotelian Propositions.

\begin{tabular}{||l|l|l||}
\hline Name & Symbol & Translation in English \\
\hline Universal affirmative & A & Every S is P (All S are P) \\
Universal negative & E & No S is P (All S are not P) \\
Particular affirmative & I & Some S are P \\
Particular negative & O & Some S are not P \\
\hline
\end{tabular}

Yet dealing with negative statements is often very useful in particular in preference matrices where positive and negative terms may appear [16]]. For instance, let $f_{i j}$ be the preference degree of alternative $i$ over alternative $j$. If $f_{i j}$ is "much less preferred", $f_{j i}$ should be "much more preferred". But the real cases are rarely so simple. $f_{j i}$ can be a more complex negation of $f_{i j}$. Of course, loosing reciprocity in the matrices is a problem, but when computing with words, this kind of property cannot be guaranteed. Thus this article tries to imagine how to model different kinds of linguistic negation, in order to perform a semantic computation with words.

The paper is organized as follows: Section 2 is dedicated to the related works about semiotics and semantics. Then the notions of negation, contrary, contradiction, etc. are highlighted in Section 3 while Section 4 gives clues to imagine a simple model to represent the negation. Finally Section 5 concludes this study, while giving some ideas for future works.

\section{Related works}

To be efficient, computing with words needs to take into account features of the language. For example, in a hospital, when doctors give advices about a same patient, a decision will have to be made to sum up the advice. Another example is when patients are asked to give comments, proposals and opinion prior to the making decisions on specific equipments, plans and 
programmes. Questionnaires and pain scales that are usually dedicated to persons being impaired (visually impaired, mobility impaired, etc.) measure a patient's pain intensity with numerical scales [17]. But pain assessments should be enhanced with linguistic scales to better catch the feeling of the patients.

Semiotics is the study of the meaning of words, signs, sign processes, etc. Three dimensions are distinguished: semantics, syntax and pragmatics. Semantics that aims to study the signs and their meaning is the one interesting for the current work. Yet an stimulating proposal has been suggested by Greimas in the 60's: the semiotic square [15] derived from Aristotle's square of opposition and composed of four terms: S1, S2, S1 and $\sim \mathrm{S} 2$. $\mathrm{S} 1$ and $\mathrm{S} 2$ have an opposition relationship while $\mathrm{S} 1$ and $\sim \mathrm{S} 1, \mathrm{~S} 2$ and $\sim \mathrm{S} 2$ are in contradiction. This permits to reflect that there are terms that are antonyms only in a certain context. For example, in a advertisement, one can read: "With car X, no need to select between comfort and sportiness". In this case, "comfort" seems to be an antonym of "sportiness", which is not the case, generally speaking.

\section{Negation and Contradiction}

According to Greimas, antinomy is represented by two kinds of relationships: contradiction and contrary. Two terms are contradictory when the affirmation of one is the negation of the other, and vice-versa (the principle of the excluded middle is fulfilled). Two terms are contrary when the affirmation of one is the negation of the other, but the negation of one is not necessary equivalent to the affirmation of the other.

Recently, an alternative to the classification of Greimas has been proposed by Franceschi [18] to take into account a kind of neutral term. Indeed, in Greimas' square, pairs of words only express the contrary (negation) of eachother, i.e. the strong negation. Weak negation which is related to indifference is lacking in the square [19]. So the square is replaced by a matrice of concepts providing six terms instead of four. For a given duality $\mathrm{A} / \overline{\mathrm{A}}$, we have thus the six following canonical poles: $\left\{\mathrm{A}_{+}, \mathrm{A}_{0}, \mathrm{~A}_{-}, \overline{\mathrm{A}}_{+}, \overline{\mathrm{A}}_{0}, \overline{\mathrm{A}}_{-}\right\}$that depend on a contrary component $c$ and a canonical polarity $p$ (cf. Table 2 ).

A duality can be, e.g. Exceptional/Normal, Audacity/Cowardice, etc. $\mathrm{A}_{0}$ and $\overline{\mathrm{A}}_{0}$ are dual or inverse; $\mathrm{A}_{+}$and $\overline{\mathrm{A}}_{-}$are contraries (or antinomical) in the same way as $\mathrm{A}_{-}$and $\overline{\mathrm{A}}_{+} ; \mathrm{A}_{+}$and $\overline{\mathrm{A}}_{+}$are complementary, in the same way as $\mathrm{A}_{-}$and $\overline{\mathrm{A}}_{-} ; \mathrm{A}_{+}$and $\mathrm{A}_{-}$are corollary, in the same way as $\overline{\mathrm{A}}_{+}$ and $\bar{A}_{-} ; A_{0}$ and $A_{+}$are related (connected), in the same way as $A_{0}$ and $\mathrm{A}_{-}, \overline{\mathrm{A}}_{0}$ and $\overline{\mathrm{A}}_{+}, \overline{\mathrm{A}}_{0}$ and $\overline{\mathrm{A}}_{-} ; \mathrm{A}_{0}$ and $\overline{\mathrm{A}}_{+}$are anti-connected, in the same 
way as $\mathrm{A}_{0}$ and $\overline{\mathrm{A}}_{-}, \overline{\mathrm{A}}_{0}$ and $\mathrm{A}_{+}, \overline{\mathrm{A}}_{0}$ and $\mathrm{A}_{-}$.

Table 2. The six canonical poles, according to Franceschi.

\begin{tabular}{|l|c|c|c|c|c|c|}
\hline & $\mathrm{A}_{+}$ & $\mathrm{A}_{0}$ & $\mathrm{~A}_{-}$ & $\overline{\mathrm{A}}_{+}$ & $\overline{\mathrm{A}}_{0}$ & $\overline{\mathrm{A}}_{-}$ \\
\hline contrary component $c$ & 1 & 1 & 1 & -1 & -1 & -1 \\
\hline canonical polarity $p$ & 1 & 0 & -1 & 1 & 0 & -1 \\
\hline
\end{tabular}

Taking for instance the duality Audacity/Cowardice, we obtain the scheme of Figure 1.

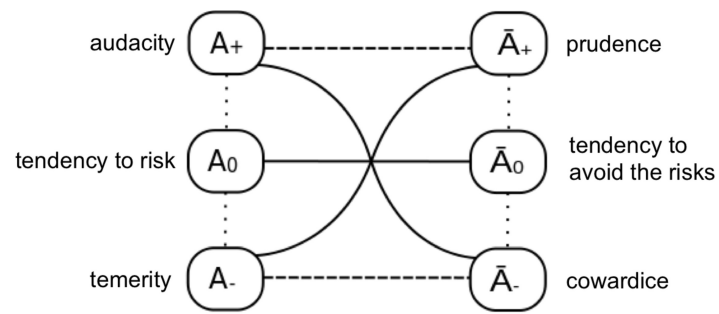

Fig. 1. The matrix of concepts for Audacity/Cowardice, according to Franceschi.

But how to model those concepts?

\section{A proposal to model the linguistic negation}

Among the combinations of relations existing between the 6 canonical poles we shall emphasize the following relations: duality, antinomy, complementarity and anti-connexity, which represent the linguistic negation. It is obvious that four distinct negation operators should be proposed.

The other two (corollary relation and connexity) are similar to a kind of synonymy, so they should be represented by resemblance operators or implication operators.

From Table 2, we assume that two components are compulsory to express the relations between the poles: $c$ and $p$. These two components are related to each other so we can draw a two-dimensional graphic. The $x$-axis indicates the contrary component $c$ and the $y$-axis indicates the canonical polarity $p$. Using a partitioning with fuzzy linguistic 2-tuples (for more details, see a complete review [20]) for both axes permits to put linguistic terms while assigning them a membership value, depending on whether they really belong to this "class" or not. What we call "class" here is a 
semantic network of linguistic terms. Finally, the membership value adds a third dimension to the graphic. Figure 2 depicts the three intersecting dimensions of linguistic negation for the duality Audacity/Cowardice.

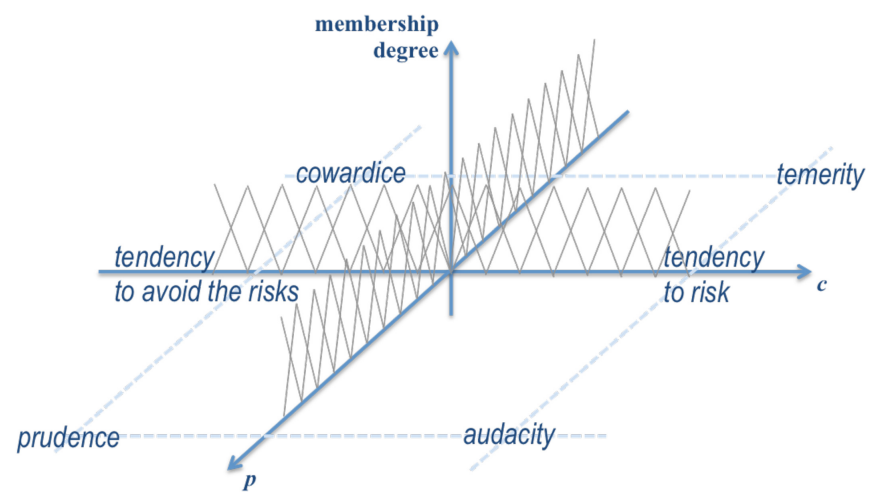

Fig. 2. Modeling the linguistic negation thanks to fuzzy linguistic 2-tuples. Example with the duality Audacity/Cowardice.

On that basis, four distinct negation operators will be defined: $\operatorname{Neg}_{d}($.$) ,$ $\mathrm{Neg}_{\mathrm{a}}(),. \mathrm{Neg}_{\mathrm{c}}($.$) and \mathrm{Neg}_{\mathrm{n}}($.$) to express duality, antinomy, complementarity$ and anti-connexity.

(i) $\mathrm{Neg}_{\mathrm{d}}($.$) is an 2-dimensional operation because the only interesting axis$ is the contrary component $c$. So it can be defined through existing 2-tuple negation operators, such as $N e g\left(\left(s_{i}, \alpha\right)\right)$ [20].

(ii) $\mathrm{Neg}_{\mathrm{a}}($.$) is an 3-dimensional operation because both axis c$ and $p$ are important. So it must be defined specifically.

(iii) $\operatorname{Neg}_{c}($.$) is an 3-dimensional operation because both axis c$ and $p$ are important. So it must be defined specifically.

(iv) $\operatorname{Neg}_{\mathrm{n}}($.$) is an 3-dimensional operation because both axis c$ and $p$ are important. So it must be defined specifically.

As we can see, there is a need to define those new operators since they actually represent the wide majority of the terms. Indeed, for each duality, among the 15 possible relations (we should say: the 15 possible "classes"), there is only one dual term pair, but there are two antinomy term pairs, two complementary term pairs and four anti-connected term pairs. Of course, the size of each "class" (i.e. the number of dual term pairs, the number of antinomy term pairs, etc.) depends on the language. 


\section{Conclusions}

In this paper we have highlighted the existing works in the literature regarding the linguistic negation. Then we focused on Franceschi's matrices of concept and proposed to shed new light on the linguistic negation in building bridges between Franceschi's work and the fuzzy linguistic 2-tuple model. As a future work, we will propose formal definitions of the four negation operators in the fuzzy linguistic 2-tuple model. Long term, we will propose to consider the unbalanced linguistic term sets to achieve a real semantic computing with words.

\section{References}

1. M. Espinilla, N. Halouani and H. Chabchoub, Int. J. Computational Intelligence Systems 8, 250 (2015).

2. L. A. Zadeh, Fuzzy Systems, IEEE Transactions on 4, 103 (1996).

3. L. A. Zadeh, Information Control 8, 338 (1965).

4. F. Herrera and L. Martínez, IEEE Transactions on Fuzzy Systems 8, 746 (2000).

5. R. M. Rodríguez and L. Martínez, International Journal of General Systems 42, 121 (2013)

6. J. Wang and J. Hao, IEEE Transactions on Fuzzy Systems 14, 435 (2006).

7. M. Abchir and I. Truck, Kybernetika 49, 164 (2013), Institute of Information Theory and Automation (Academy of Sciences of the Czech Republic).

8. J. Mœschler, Argumentation 6, 51 (1992).

9. V. Torra, International Journal of Intelligent Systems 11, 975 (1996).

10. D. Pacholczyk, M. Quafafou and L. Garcia, Optimistic vs. pessimistic interpretation of linguistic negation, in Artificial Intelligence: Methodology, Systems, and Applications, (Springer, 2002) pp. 132-141.

11. P. Larrivée and C. Lee, Negation and polarity: Experimental perspectives (Springer, 2016).

12. O. Jespersen, Negation in English and other languages, Historisk-filologiske Meddelelser, Vol. 1(5) (A. F. Høst, 1917).

13. F. H. Paricio, Langages 40, 73 (2006).

14. L. A. Phuong and T. D. Khang, International Journal of Computational Intelligence Systems 7, 556 (2014).

15. A. J. Greimas, Structural Semantics: An Attempt at a Method. Translated in 1983 by McDowell, Schleifer, and Velie (University of Nebraska Press, 1966).

16. Y. Dong, Y. Xu and S. Yu, Fuzzy Systems, IEEE Transactions on 17, 1366 (2009).

17. C. T. Hartrick, J. P. Kovan and S. Shapiro, Pain Practice 3, 310 (2003).

18. P. Franceschi, Semiotica 139, 121 (2002).

19. P. Franceschi, Semiotica 152, 251 (2005).

20. L. Martínez, R. M. Rodríguez and F. Herrera, The 2-tuple Linguistic Model - Computing with Words in Decision Making (Springer, 2016). 